\section{Stigma: the feelings and experiences of 46 people with mental illness}

\author{
Qualitative study \\ SOKRATIS DINOS, SCOTT STEVENS, MARC SERFATY, SCOTT WEICH \\ and MICHAEL KING
}

\begin{abstract}
Background Stigma defines people in terms of some distinguishing characteristic and devalues them as a consequence.
\end{abstract}

\begin{abstract}
Aims To describe the relationship of stigma with mental illness, psychiatric diagnosis, treatment and its consequences of stigma for the individual.
\end{abstract}

\begin{abstract}
Method Narrative interviews were conducted by trained users of the local mental health services; 46 patients were recruited from community and day mental health services in North London.
\end{abstract}

Results Stigma was a pervasive concern to almost all participants. People with psychosis or drug dependence were most likely to report feelings and experiences of stigma and were most affected by them. Those with depression, anxiety and personality disorders were more affected by patronising attitudes and feelings of stigma even if they had not experienced any overt discrimination. However, experiences were not universally negative.

\section{Conclusions Stigma may influence} how a psychiatric diagnosis is accepted, whether treatment will be adhered to and how people with mental illness function in the world. However, perceptions of mental illness and diagnoses can be helpful and non-stigmatising for some patients.

Declaration of interest None.
Stigma is a social construction that defines people in terms of a distinguishing characteristic or mark and devalues them as a consequence (Jones et al, 1984; Crocker et al, 1998; Biernat \& Dovidio, 2000; Dovidio et al, 2000). A stigmatised person may be regarded as not quite human (Goffman, 1963). According to Goffman's original formulation, the stigma of mental illness can be either discrediting (when it is obvious to others) or discreditable (when it is not obvious to the others). This depends upon the nature and severity of the illness, the individuals' responses to it and their willingness to reveal it to others. Although it may not be possible for people to conceal a mental illness, how to manage information about their condition can be a potent source of stress, anxiety and further feelings of stigma even in the absence of any direct discrimination. Most research on stigma has concerned public reactions to the mentally ill (Byrne, 1977; Bhugra, 1989; Ritchie, 1994; Wolff et al, 1996). Little account has been taken of the personal experiences of stigma of people with mental illness. We aimed to describe stigma on the basis of qualitative accounts by people with mental illness; to explore the relationship between stigma and psychiatric diagnosis, perceptions of illness and treatment; and to explore the consequences of stigma on people's lives. Unlike previous research (e.g. Mental Health Foundation), this was a collaboration between academics/health care professionals and mental health service users.

\section{METHOD}

This project was conducted in collaboration between academic researchers and members of a local service user group.

\section{Participants}

We recruited a purposive sample of 46 people with different psychiatric diagnoses, ages, gender and ethnicity (Table 1) from mental health user groups, day centres, crisis centres and hospitals in north London. We relied on patients' own reports of their diagnoses as the most relevant description of their illnesses for the purposes of this study.

\section{The interviewers}

Two users of the local mental health services received training in the basic approach to qualitative research and how to conduct narrative interviews. The training package involved: general introduction to qualitative research and the distinction from quantitative methods; interviewing skills such as establishing rapport and empathy, gaining trust, avoiding leading interviews or imposing one's own judgement or opinions, and appropriate use of emotion; and professional and ethical boundaries. It involved role playing for dealing with difficult settings, ensuring safety and giving feedback to interviewees. One of the aims of training mental health service users was to facilitate rapport between researchers and interviewees and, further, to examine the feasibility of user involvement in academic research. We wanted the interviewees to feel relaxed enough in the interview to share the key aspects of their identity and their experience of mental distress (Mental Health Foundation, 2000) and thus pave the way for future user involvement at various levels of research.

\section{Procedure}

Each interview began with a description of the participant's history of mental health problems, diagnosis, treatment and social environment, such as friends and family. Participants were asked to talk about the impact of their mental health problems on their work and private life. Where possible, we avoided using the word stigma so as not to lead the participants. Interviews took an average of $45 \mathrm{~min}$ and were tape recorded and transcribed. Participants were assured of anonymity and all gave permission for the conversation to be recorded. Each was given a small payment in appreciation for their time. The Camden and Islington local research ethics committee approved the study.

\section{Analysis}

We read the transcribed interviews in their entirety to identify themes and place 
Table I Demographic and diagnostic profile of participants

\begin{tabular}{|c|c|c|}
\hline & $\begin{array}{c}\text { Men } \\
n\end{array}$ & $\begin{array}{c}\text { Women } \\
n\end{array}$ \\
\hline \multicolumn{3}{|l|}{ Diagnosis } \\
\hline Schizophrenia & 8 & 5 \\
\hline Bipolar affective disorder & 2 & 3 \\
\hline $\begin{array}{l}\text { Dual diagnosis (psychosis and } \\
\text { drug dependence) }\end{array}$ & 6 & 7 \\
\hline Major depression & 4 & I \\
\hline Mixed anxiety and depression & 2 & 4 \\
\hline Eating disorder & I & I \\
\hline Personality disorder & 1 & I \\
\hline \multicolumn{3}{|l|}{ Age (years) } \\
\hline $20-29$ & 2 & 2 \\
\hline $30-39$ & 10 & 5 \\
\hline $40-49$ & 5 & 7 \\
\hline $50-59$ & 2 & 4 \\
\hline 60 and over & 5 & 4 \\
\hline \multicolumn{3}{|l|}{ Ethnic origin } \\
\hline British & 17 & 16 \\
\hline Other European & 2 & I \\
\hline African/African-Caribbean & 5 & 3 \\
\hline Indian, Pakistani, Bangladeshi & 0 & 2 \\
\hline
\end{tabular}

individual accounts in the context of participants' backgrounds and mental health problems. Each interview was deconstructed sentence by sentence to identify key themes, names were assigned and example quotations for each theme were noted (Smith, 1995). Themes were identified by a close study of the data by all the authors, who reached consensus on those of greatest importance based on the research questions. Then the themes were context analysed (Mostyn, 1985; Dey, 1993). These categories were compared across scripts to build up concepts that extended beyond simple descriptive categories. As the data were coded, further themes emerged: these were then combined and sorted into significant and meaningful areas, and frequency counts were made of the major themes. Interrater reliability was tested by another rater who coded approximately half of the extracts using the themes developed during the analysis. Reliability for each main category was between $85 \%$ and $100 \%$.

\section{RESULTS}

The number of participants who provided evidence for each category is reported below, with the total number of extracts concerning that category from all the interviews shown in parentheses.

\section{Types of stigma}

Participants talked a great deal about stigma. The stigma very often took different forms, depending on the context. However, two distinct sub-categories that emerged were subjective feelings of stigma (Table 2), even in the absence of any discrimination, and stigma in the context of overt discrimination (Table 3).

\section{Subjective feelings of stigma}

As Table 2 shows, 41 out of 46 people expressed feelings of stigma. In particular, 18 people with psychosis, 13 people with non-psychosis and 10 people with dual diagnoses reported feelings of stigma in the absence of any direct discrimination. The participants' feelings of stigma were often related to the psychiatric diagnosis. As we can see in Table 2, 19 participants expressed feelings of stigma following their diagnosis: 16 participants with psychotic disorders (schizophrenia and bipolar affective disorder) (19 extracts) and 3 of the participants with non-psychotic disorders (6 extracts) recalled feeling stigmatised when they received their diagnosis. The same was not found in people with a dual diagnosis (e.g. drug dependency and depression), who seemed already to be aware of the magnitude and nature of their problems.

\begin{abstract}
'Schizophrenic is the worst diagnosis because l've heard it in the newspapers and on TV, that they are really mad schizophrenic people, they are very dangerous to society, they've got no control. So obviously I came under that category. (African-Caribbean woman 4I, schizophrenia)
\end{abstract}

Although treatment was not discussed extensively with participants, four people with schizophrenia (6 extracts) expressed negative views of their treatment because of the stigma attached to it.

'Well I'm too worried about telling people I'm on medication. There are very, very few people that I talk about the ECT to... because it does feel... well I don't really want to talk about it because I hate it and it's horrible and also I feel there is big stigma attached and if they hear

Table 2 Number of extracts for each type of feeling of stigma (number of participants in parentheses)

\begin{tabular}{|c|c|c|c|c|c|c|c|}
\hline Patient group & Diagnosis & Treatment & Disclosure & $\begin{array}{c}\text { Disclosure of } \\
\text { edited diagnosis }\end{array}$ & Media & $\begin{array}{l}\text { Anticipations of } \\
\text { negative events }\end{array}$ & Total \\
\hline Psychosis & $19(16)$ & $6(4)$ & $31(18)$ & $6(4)$ & $10(7)$ & - & $72(18)$ \\
\hline Non-psychosis & $6(3)$ & - & $19(12)$ & - & - & $9(6)$ & $34(13)$ \\
\hline Dual diagnosis & - & - & $15(10)$ & - & - & - & $15(10)$ \\
\hline Total & $25(19)$ & $6(4)$ & $65(40)$ & $6(4)$ & $10(7)$ & $9(6)$ & $12 \mid$ \\
\hline
\end{tabular}

Table 3 Number of extracts for each type of overt discrimination stigma (number of participants in parentheses)

\begin{tabular}{|c|c|c|c|c|c|c|}
\hline Patient group & Verbal abuse & Physical abuse & Loss of contacts & Patronising attitudes & Discrimination & Total \\
\hline Psychosis & II (8) & $12(8)$ & $18(9)$ & - & $13(9)$ & $54(14)$ \\
\hline Non-psychosis & $8(6)$ & - & I (I) & $10(6)$ & I (I) & $20(7)$ \\
\hline Dual diagnosis & $7(5)$ & $8(5)$ & $8(6)$ & $6(4)$ & $6(4)$ & $35(8)$ \\
\hline Total & $26(19)$ & $20(13)$ & $27(16)$ & $16(10)$ & $20(14)$ & 109 \\
\hline
\end{tabular}


about that they'd think I was really mad.' (White British woman, 4I, schizophrenia)

One aspect of stigma that appeared in 41 out of 46 interviews was anxiety about how to manage information regarding illness and whether to disclose it or not to friends, family and prospective employers. Eighteen people with psychosis (31 extracts), 12 people with depression-related disorders (19 extracts) and 10 people with dual diagnosis (15 extracts) made 65 statements in total regarding disclosure.

'I didn't say anything to my family 'cause I thought they would be appalled actually, they're very, very, my mother in particular, very moralistic. The whole idea of not working, not earning a living, being on benefits or anything is appalling as far as she is concerned.' (White British woman, 33, eating disorder/depression)

However, four participants with a diagnosis of schizophrenia (6 extracts) seemed to be even more concerned about how to manage information about their illness and they occasionally decided to disclose an edited version of their diagnosis that they felt would be less stigmatising.

'Basically, what I told them at work was that I'd got severe depression and most of them are ok with that... Well, l've only told them an edited version ... if anybody at work or my professional body knew that l'd got schizo-anything I wouldn't be allowed to practise.' (British woman, 40, schizophrenia)

Representations of mental illness in the media emerged as a sub-theme in the narratives of seven people with a diagnosis of schizophrenia (10 extracts), where it appeared to be a major source of discomfort.

'It's just the stigma that's attached to schizophrenia. If it's on the news or TV it's usually because they've brandished a sword on the high street or attacked someone. There's never a story about a schizophrenic who saves life of granny who falls in canal.' (African man, 33, schizophrenia)

Concern about the media was not an issue for six people with depression and/or anxiety (9 extracts) who were more likely to fear overt discrimination, possibly because of depressive thinking and the anticipation of negative events in the future.

'Because people don't understand, if they know that I've been off work because of mental ill health they may choose to use somebody else rather than me.' (British man, 38, depression)

\section{Overt discrimination}

In total 29 of the participants - 14 people with psychosis, 7 people with non-psychosis and 8 people with dual diagnoses - talked a great deal about personal harassment, either verbal or physical, or through actions such as malicious property damage (Table 3). Eight people with psychosis (11 extracts), six people with non-psychotic disorders (8 extracts) and five people with dual diagnosis (especially depression and drug dependence) (7 extracts) reported having been verbally abused.

'I said l'd go to a therapeutic day centre in Kentish Town... and all I got back from this was - and how much do you cost Camden Council, you cost the tax payer money, so you sit around at Social Services doing nothing all day and you call that a life.' (British man, 43, anxiety/depression)

Physical violence was a common theme but was largely confined to eight people with psychotic illnesses (12 extracts) and five people with drug dependence $(8$ extracts).

'The whole street - they set dogs on me. l'd go in the shops and the children would come and spit on me and stuff like that.' (AfricanCaribbean woman, 4l, bipolar affective disorder)

Individuals within these diagnostic groups felt also that people stopped contact with them because of their illness. Nine people with psychosis (18 extracts), six people with drug dependence ( 8 extracts) and only one participant with depression (1 extract) reported many such instances.

I've had moments when I was talking to someone quite happily, mentioned the sheer fact that I suffer from mental health problems and I turned to talk to someone else and their back turned, they're heading for the door literally.' (AfricanCaribbean man, 33, schizophrenia)

On the other hand, people with diagnoses of non-psychotic disorders tended to report less severe forms of discrimination and were more likely to report being patronised. Six people with depression (10 extracts) and four people with dual diagnoses (6 extracts) reported having been patronised.

$\therefore$. . and they don't speak to you like an adult very often. They'll use words like, you know, don't be cheeky, something like that, which you would never say.' (British woman, 33, depression/drug dependence)

Overt discrimination was also reported in work, academic and treatment settings. Nine participants with psychosis (13 extracts) as well as one participant with depression (1 extract) and four participants with dual diagnosis (6 extracts) considered that they had been discriminated against and had failed to be selected by colleges or employers.
'At one point I said to my headmaster that l'd got manic depression and he never said anything and then at work I started crying and they used that incident to get rid of me ...' (African woman, 33 , borderline personality disorder)

\section{Perceived consequences of stigma}

The perceived consequences of stigma appeared to differ according to whether or not participants had experienced overt discrimination or persecution from others as a result of the mental health problems.

\section{Consequences arising from subjective feelings of stigma}

As Table 4 shows, 28 of the participants ( 8 with psychosis, 12 with non-psychosis and 8 with dual diagnoses) talked about the consequences of subjective feelings of stigma in their lives. In general, participants who reported being given diagnoses of depression, anxiety and/or personality disorders reported more consequences of feelings of stigma than the other diagnostic groups (Table 4). Twelve of those participants, as opposed to eight participants with psychosis and eight participants with dual diagnoses, reported the majority of feelings of stigma (59 extracts). The most common consequences of feelings of stigma revolved around anger, depression, fear, anxiety, feelings of isolation, guilt, embarrassment and prevention from recovery or avoidance of help-seeking (Table 4). An example of a participant who refused to be hospitalised because of the stigma attached is as follows:

\footnotetext{
'I regret not going to the hospital. I listened to too many people and I suddenly thought I am going to be labelled a loony. I wasn't aware obviously because it hadn't happened to me before so I was... yes it did stop me from going there.' (White British man, 43, anxiety-depression)
}

\section{Consequences of overt discrimination}

If we now look at Table 5 we can see that 30 participants in total (14 with psychosis, 6 with non-psychosis and 10 with dual diagnoses) talked about the consequences of having experienced overt discrimination. As opposed to the consequences of feelings of stigma, the consequences of stigma in the form of overt discrimination were reported more often by participants with a diagnosis of a psychotic disorder because 14 of them reported far more such instances (59 extracts) than any other diagnostic group. The consequences involved anger, embarrassment, fear, isolation and feelings of depression (Table 5). For example: 
Table 4 Consequences of feelings of stigma - number of extracts for each category (number of participants in parentheses)

\begin{tabular}{|c|c|c|c|c|c|c|c|c|c|}
\hline Patient group & Sad/bad & Anger & Fear & Guilt & Embarrassment & Isolation & Worry & Prevents recovery & Total \\
\hline Psychosis & $6(4)$ & $5(2)$ & $6(3)$ & $6(4)$ & $4(2)$ & $5(2)$ & 7 (4) & - & $39(8)$ \\
\hline Non-psychosis & - & $7(4)$ & $7(4)$ & $5(3)$ & $10(6)$ & $13(8)$ & $9(5)$ & $8(4)$ & $59(12)$ \\
\hline Dual diagnosis & $6(4)$ & $4(2)$ & $8(6)$ & $4(3)$ & $3(2)$ & $4(2)$ & $6(2)$ & - & $35(8)$ \\
\hline Total & $12(8)$ & $16(8)$ & $21(13)$ & $15(10)$ & $17(10)$ & $22(12)$ & $22(\mathrm{II})$ & $8(4)$ & 133 \\
\hline
\end{tabular}

Table 5 Consequences of overt discrimination - number of extracts for each category (number of participants in parentheses)

\begin{tabular}{lrrcccc}
\hline Patient group & Sad/bad & Anger & Embarrassment & Fear & Isolation & Total \\
\hline Psychosis & $16(9)$ & $15(9)$ & $7(3)$ & $5(2)$ & $5(2)$ & $48(14)$ \\
Non-psychosis & $8(4)$ & $7(4)$ & - & - & $10(4)$ & $25(6)$ \\
Dual diagnosis & $14(9)$ & $4(2)$ & $6(3)$ & $6(2)$ & - & $30(10)$ \\
Total & $38(22)$ & $26(15)$ & $13(6)$ & $11(4)$ & $15(6)$ & 103 \\
\hline
\end{tabular}

'It hurts, it's like... my two little nephews were there and Ryan wouldn't come near me, I don't know why, he must have been able to sense something. . . It makes you feel bad, it makes you feel even worse... when people don't trust you and you're going to do something to someone. I suppose it's understandable really, maybe if I was them I don't know if I'd feel that way.' (British man, 38, schizophrenia and forensic history)

\section{Positive outcomes and/or lack of stigma}

Very often participants' discourses were not negative and were not related to stigma. A total of 39 of the 46 participants (17 with psychosis, 12 with non-psychosis and 10 with dual diagnoses) talked about the positive side of having a mental illness (Table 6). Sixteen participants accepted their diagnosis and as a consequence were better adjusted ( 28 extracts). For example:

'I always knew I had a mental illness so I knew something was wrong with me. It was just the diagnosis that - it's just a name, I knew l'd got a mental illness so I always felt quite fed up about that. They just diagnosed it. It didn't surprise me at all.' (White British man, 37, schizophrenia)

A number of participants expressed relief at having been given a diagnosis. This was most apparent in people with depression and/or anxiety, of whom eight reported feeling relieved (16 extracts), compared with only one participant with schizophrenia (1 extract) and two participants with dual diagnosis (4 extracts).

'First of all I was relieved, the first time I saw the psychiatrist I talked to him for three hours. To have someone say that what I was feeling was not that unusual. I thought I was the only person in the world who felt like that.' (White British woman, 40, depression)

Participants' positive perceptions were also related to their treatment. Three participants with a psychotic disorder 16 extracts), two participants with depression and/or anxiety (4 extracts) and two participants with a dual diagnosis (5 extracts) expressed a positive attitude towards their treatment.
I'm fine with the treatment because I know it keeps me sane. I have got an illness I'm aware of that and I know it's true. I need it kept under control. I don't want to be running down the street this and that.' (African-Caribbean man, 35, schizophrenia)

Participants also mentioned positive outcomes of their illness and some said that their illness did not prevent them from achieving things at a social or a personal level. That was most often the case in people with depression, anxiety and drug dependency. Five participants with psychosis (10 extracts), nine participants with depression and/or anxiety (15 extracts) and eight participants with dual diagnosis (14 extracts) made positive statements about their illness.

'I feel that if I survive it I've been through a very privileged experience and that I can actually make something of it. . I will have had a rare experience to get to know myself better and gain more insight, more wisdom. . .I think the people I've met who've had mental health problems, I feel privileged to have met, from all walks of life that I would never have encountered. Also l've met the most extraordinary professionals...। find that an amazing experience.' (White British woman, 5I, bipolar affective disorder)

A significant number of people had little difficulty in disclosing information about their illness and did not feel any shame or anticipate negative reactions. Eight people with psychosis (10 extracts), eight people with depression and anxietyrelated disorders (9 extracts) and five people with dual diagnosis (7 extracts) talked about a lack of any feelings of stigma.

Table 6 Positive outcomes and lack of stigma - number of extracts for each category (number of participants in parentheses)

\begin{tabular}{|c|c|c|c|c|c|c|c|c|}
\hline Patient group & $\begin{array}{c}\text { Acceptance of } \\
\text { diagnosis }\end{array}$ & $\begin{array}{c}\text { Relief after } \\
\text { diagnosis }\end{array}$ & $\begin{array}{l}\text { Positive } \\
\text { treatment } \\
\text { attitude }\end{array}$ & $\begin{array}{c}\text { Positive illness } \\
\text { outcomes }\end{array}$ & $\begin{array}{l}\text { Lack of feelings } \\
\text { of stigma }\end{array}$ & $\begin{array}{l}\text { Lack of overt } \\
\text { discrimination }\end{array}$ & $\begin{array}{c}\text { Perceived } \\
\text { positive public } \\
\text { attitudes }\end{array}$ & Total \\
\hline Psychosis & $15(10)$ & I (I) & $6(3)$ & $10(5)$ & $10(8)$ & 14 (7) & $8(5)$ & $64(17)$ \\
\hline Non-psychosis & $5(2)$ & $16(8)$ & $4(2)$ & $15(9)$ & $9(8)$ & $7(6)$ & $3(2)$ & $59(12)$ \\
\hline Dual diagnosis & $8(4)$ & $4(2)$ & $5(2)$ & 14 (8) & 7 (5) & $8(5)$ & - & $46(10)$ \\
\hline Total & $28(16)$ & $2 \mathrm{I}(\mathrm{II})$ & $15(7)$ & $39(22)$ & $26(2 I)$ & $29(18)$ & II (7) & 169 \\
\hline
\end{tabular}


'I consider it's part of me in a sense that people take me as me... I'm not ashamed of what I feel or what I have. I don't hide it from people. If they don't like it then fine, that's not important, it's their loss not mine...' (White British woman, 32, bipolar affective disorder)

Similarly seven participants with psychosis (14 extracts), six participants with depression and/or anxiety (7 extracts) and five participants with dual diagnosis (8 extracts) had not experienced overt discrimination and some had even received positive reactions from others.

'I haven't experienced any problems with people regarding my mental illness. They're very nice towards me. Even in the centre, they're so cooperative.' (African man, 77, schizophrenia)

Finally, five participants with psychosis (8 extracts) and two participants with depression (3 extracts) expressed the opinion that the general public was positive towards people with mental illness.

'Well I think probably it's a contemporary issue now, maybe 30 or 40 years ago mental illness was considered rather untreatable . . but over the years people have become more and more understanding and in some cases sympathetic towards mental health problems.' (White British man, 62, depression)

It was apparent, however, that no participant with drug dependence shared this positive view.

\section{DISCUSSION}

\section{Principal findings}

Stigma about mental illness was a pervasive and serious concern to most, but not all, participants. Stigma can take different forms and be experienced in different domains such as diagnosis, treatment, disclosure and social situations. Experiences of overt discrimination and concerns about the representation of mental illness in the media were largely confined to people with psychosis and drug dependence. Participants with depression, anxiety and personality disorders were the most likely to be affected by feelings of stigma even in the absence of such overt discrimination. They were also more concerned with patronising attitudes from family, friends and work colleagues. One important outcome is that some people may not ask for help or may refuse to be hospitalised for fear of further stigmatisation. Although treatments were not often linked to stigma, particular therapies such as lithium prophylaxis and electroconvulsive therapy could intensify feelings of stigma and make disclosure even more difficult. However, we found that the perceptions of illness and stigma were not always negative. Several individuals denied either feelings of stigma or the experience of overt discrimination, and instead reported positive outcomes regarding their illness.

\section{Experiencing stigma}

Stigma can be a challenge to one's humanity and is personally, interpersonally and socially costly (Biernat \& Dovidio, 2000). This was particularly the case in psychotic illness when people reported concealing the true nature of their illness by telling others that they had depression or a physical disorder. Only participants with schizophrenia, bipolar affective disorder and drug addiction reported experiencing physical violence, verbal abuse and loss of contact with people because of their illness. Although their unusual behaviour might have provoked negative reactions, or made them more vulnerable to physical assault, it could equally well be the case that the general public holds more negative attitudes towards people with these illnesses. On the other hand, although people with depression, anxiety and personality disorders did not express very strong views about the general public and did not appear to have undergone the same degree of discrimination, they did not seem any more at ease with their diagnosis and had to face many of the same challenges.

\section{Managing information}

Concern about disclosure emerged as a major theme in this study. Managing a discreditable identity that is not always apparent to others, such as mental illness, can be a powerful source of anxiety (Goffman, 1963). Participants' attempts to avoid disclosure resulted in stress, isolation and a sense of shame. Feeling stigmatised can occur in the absence of any direct discrimination (Jacoby, 1994).

\section{Consequences of stigma}

Goffman (1963) suggested that stigma can lead to isolation and our results suggest that this is still the case today. The participants' acceptance of a negative view of mental illness led to stress and anguish; in many cases they seem to have concluded that the prejudice was justified and that they were incapable of independent living (Corrigan \& Penn, 1999). Increased stress and feelings of conflict (Farina et al, 1974) may result in further psychological problems such as depression (Link et al, 1997), anxiety (Farina, 1981) and low self-esteem (Link, 1987). Some sufferers may even avoid or refuse help for fear of further stigmatisation.

\section{Forms of stigma and forms of mental illness}

Stigma takes many forms, but our findings confirm that those who have experienced mental illness distinguish between acts of overt discrimination and subjective feelings of stigma. The narratives described in this study show that the nature, intensity and consequences of stigma vary with psychiatric diagnosis, being different for those with psychotic and non-psychotic disorders. Individuals with drug dependency problems tend to resemble the former in their experiences of stigma, and were characterised by more frequent acts of overt discrimination. Whereas those with nonpsychotic illnesses may not have experienced such tangible manifestations of their stigma, their subjective 'internalised' feelings about themselves were evident. Although our data are cross-sectional, it is conceivable that feelings of inferiority and fear of negative responses from others have prevented individuals from availing themselves of opportunities in their lives. Our findings are also noteworthy for revealing that perceptions of illness are not universally negative, and in some cases participants spoke of this as positively lifeenhancing. Such findings raise questions about factors that might protect individuals against the feelings of stigma and about different methods of coping with the feelings that arise from the experience of mental illness.

Finally, although these accounts cannot tell us how negative attitudes arise in society or why they are so prevalent, they indicate how we might plan more sensitive services and influence public attitudes to mental illness. We are using these data to develop a quantitative measure of felt and enacted stigma that may be applied in evaluations of mental health services and treatments.

\section{ACKNOWLEDGEMENTS}

We thank all the mental health service users who agreed to be interviewed. We also acknowledge Jennifer Shaw and Robert Watson who conducted 
the interviews, Glen Smith, Petra Boynton and Apu Chakraborty for assisting with training in qualitative research techniques and Linda Polan and Penelope Abraham for their advice on the study. This study was carried out with the support and collaboration of the Camden and Islington Mental Health and Social Care Trust.

\section{REFERENCES}

Bhugra, D. (1989) Attitudes towards mental illness: a review of the literature. Acta Psychiatrica Scandinavica, 80, $1-12$

Biernat, M. \& Dovidio, J. F. (2000) Stigma and stereotypes. In The Social Psychology of Stigma (eds T. F. Heatherton, R. E. Kleck, M. R. Hebl, et al), pp. 88-125. New York: Guilford Press.

Byrne, D. (1977) Interpersonal attraction: do we know anything and are we going anywhere? Revista Interamericana de Psicología, II, 48-55.

Corrigan, P. W. \& Penn, D. L. (1999) Lessons from social psychology on discrediting psychiatric stigma. American Psychologist, 54, 765-776.

Crocker, J., Major, B. \& Steele, C. (1998) Social stigma. In Handbook of Social Psychology, Vol. 2 (4th edn) (eds D. T. Gilbert, S. T. Fiske \& G. Lindzey), pp. 504-553. Boston: McGraw-Hill.

Dey, I. (1993) Qualitative Data Analysis. London: Routledge.

Dovidio, J. F., Major, B. \& Crocker, J. (2000) Stigma: introduction and overview. In The Social Psychology of Stigma (eds T. F. Heatherton, R. E. Kleck, M. R. Hebl, et al), pp. I-30. New York: Guilford Press.

Farina, A. (1981) Are women nicer people than men? Sex and the stigma of mental disorders. Clinical Psychology Review, I, 223-243.

Farina, A., Thaw, J. \& Loevern, J. D. (1974) People's reactions to a former mental patient moving to their neighbourhood. Journal of Community Psychology, 2. 108-112

Goffman, E. (1963) Stigma: Notes on the Management of Spoiled Identity. London: Penguin Books.

Jacoby, A. (1994) Felt versus enacted stigma: a concept revisited. Evidence from a study of people with epilepsy in remission. Social Science and Medicine, 38, 269-274.

Jones, E. E., Farina, A., Hastorf, A. H., et al (1984) Social Stigma: the Psychology of Marked Relationships. New York: W. H. Freeman.

Link, B. G. (1987) Understanding labeling effects in the area of mental disorders: an assessment of the effects of expectations of rejection. American Sociological Review, 52, 6-112.

Link, B. G., Struening, E. L., Rahav, M., et al (1997) On stigma and its consequences: evidence from a

\section{CLINICAL IMPLICATIONS}

- Stigma is a pervasive experience for almost all people using mental health services and must be considered within all therapeutic and social management plans.

- Perceived stigma and overt discrimination against people with mental illness causes distress, prevents people from disclosing their difficulties, affects how a psychiatric diagnosis is accepted and whether treatment will be adhered to, and may reduce opportunities for recovery.

- An important minority of patients find that their mental illness enhances their experience of life and relationships with others.

\section{LIMITATIONS}

- The data are based on self-reports of a cross-sectional sample of people.

- Their experiences were not corroborated in any way.

- People with mental illness who are not in contact with community mental health services were not included and, as a consequence, the sample selection was nonrandom.

SOKRATIS DINOS, MSc, Department of Psychiatry and Behavioural Sciences, Royal Free and University College Medical School, London; SCOTT STEVENS, Camden and Islington Mental Health Consortium, London; MARC SERFATY, MPhil, SCOTT WEICH, MD, MICHAEL KING, MD, Department of Psychiatry and Behavioural Sciences, Royal Free and University College Medical School, London

Correspondence: Michael King, Department of Psychiatry and Behavioural Sciences, Royal Free and University College Medical School, Royal Free Campus, Rowland Hill Street, London NW3 2PF, UK. E-mail: m.king@rfc.ucl.ac.uk

(First received 12 June 2003, final revision 26 August 2003, accepted I5 September 2003)

longitudinal study of men with dual diagnoses of mental illness and substance abuse. Journal of Health and Social Behavior, 38, 177-190.

Mental Health Foundation (2000) Strategies for Living a Report of User-led Research into People's Strategies for Living with Mental Distress. London: Mental Health Foundation.

Mostyn, B. (1985) The content analysis of qualitative research data: a dynamic approach. In The Research Interview (eds M. Brenner, J. Brown \& D. Canter). London: Academic Press.
Ritchie, M. H. (1994) Cultural and gender biases in definitions of mental and emotional health and illness. Counsellor Education and Supervision, 33 344-348.

Smith, J. A. (1995) Semi structured interviewing and qualitative analysis. In Rethinking Methods in Psychology (eds J. A. Smith, R. Harr \& L. U. Langehove), pp. 9-26. London: Sage

Wolff, G., Pathare, S., Craig, T., et al (1996)

Community attitudes to mental illness. British Journal of Psychiatry, 168, 183-190. 